\title{
Quantitative trait loci of frost tolerance and physiologically related trait in faba bean (Vicia faba $\mathrm{L}$.)
}

\author{
Mustapha Arbaoui · Wolfgang Link • \\ Zlatko Satovic · Ana-Maria Torres
}

Received: 30 November 2007 / Accepted: 25 January 2008/Published online: 5 February 2008

(C) The Author(s) 2008

\begin{abstract}
In faba bean, field based winter-hardiness is a complex trait that is significantly correlated to frost tolerance. Frost tolerance could be used to indirectly select for faba bean winter-hardiness. The aim of this study was to identify putative QTL associated with frost tolerance and auxiliary traits and to quantify the efficiency of marker assisted selection. Thus, 101 recombinant inbred lines derived from the cross between two frost tolerant lines were tested for their hardened and unhardened frost tolerance and for their leaf fatty acid content in both treatments. Significant differences among the RIL were observed for all studied traits. For frost tolerance, five putative QTL were detected; three for unhardened frost tolerance that explained $40.7 \%$ (8.6\% after crossvalidation, $\mathrm{CV}$ ) of its genotypic variance and two for hardened frost tolerance that explained $21.8 \%(1.0 \%$
\end{abstract}

M. Arbaoui · W. Link ( $₫)$

Department of Crop Sciences, Georg-August-University, Von-Siebold Str. 8, 37075 Göttingen, Germany

e-mail: wlink@gwdg.de

Z. Satovic

Department of Seed Science and Technology, Faculty of Agriculture, University of Zagreb, Svetosimunska 25, 10000 Zagreb, Croatia

A.-M. Torres

Área de Mejora y Biotecnología, IFAPA, Centro Alameda del Obispo (Junta de Andalucía), Apdo. 3092,

14080 Córdoba, Spain after CV). For fatty acid content, three QTL were detected for oleic acid content in unhardened leaves that explained $62.9 \%(40.6 \%$ after CV) of its genotypic variance. This fatty acid was significantly correlated with unhardened frost tolerance. The unbiased genotypic variance explained enabled to draw realistic prospects of MAS for frost tolerance. In this study, combined MAS was more efficient than classical phenotypic selection and was expected to be higher on larger populations at early generations. Moreover, favourable alleles inherited from the exotic line BPL 4628 could be introgressed to European winter-hardy beans for further improvement.

Keywords Vicia faba . Frost tolerance . Leaf fatty acid content - QTL · Cross-validation . MAS

\section{Introduction}

In most North and Central European countries, freezing temperatures below $-6^{\circ} \mathrm{C}$ (Herzog 1987) during winter are one of the major limitations for growing autumn-sown faba bean (Vicia faba L.). The superiority of winter types over spring types for protein and grain yield, and the crucial impact of complete overwintering on grain yield emphasise the importance of improving faba bean winter-hardiness. 
Field-based winter-hardiness is a complex trait resulting from the combined expression of several auxiliary traits such as frost tolerance and resistance to biotic winter stress. The irregular occurrence of appropriate natural freezing temperatures that allow differentiation among genotypes is also a major limitation. Unless results from many environments are available, heritability and gain from selection for winter-hardiness is expected to be low. In order to reach a high reproducibility, experiments under controlled conditions were developed to analyse frost tolerance. In several crop species, frost tolerance was found to be a main component of winter-hardiness (Rizza et al. 1994; Petcu and Terbea 1995; Arbaoui et al. 2008). The frost tolerance of a plant was defined as (1) its unhardened frost tolerance and (2) its hardening response. In potato, both traits were found to be inherited independently (Stone et al. 1993). Hardening, also known as cold acclimation is the result of an exposure to low non-freezing temperatures (Levitt 1980) which increases significantly plant frost tolerance (Herzog 1987; Rizza et al. 1994; Petcu and Terbea 1995; Badaruddin and Meyer 2001; Arbaoui and Link 2007).

Responses of plants to hardening were observed on oligogenic traits such as (1) accumulation of sucrose and other simple sugars (Pollock 1986; Santoiani et al. 1993), (2) increase of total protein concentration (Davis and Gilbert 1970; McKenzie et al. 1988), (3) accumulation of free proline (Petcu and Terbea 1995; Dörffling et al. 1997; Thomashow 1999), (4) increase of the cell membranes stability (Chandrasekar et al. 2000), (5) increase of total lipids and their polyunsaturated fatty acid content (linoleic and linolenic acids), and (6) increase of desaturase enzyme activity (Cyril et al. 2002; Wei et al. 2005). Recent studies in faba bean showed that polyunsaturated fatty acid accumulation were adaptation mechanisms to low non-freezing temperatures, but also significant correlated traits to frost tolerance (Arbaoui et al. 2008).

During the past 15 years, many genetic linkage maps were developed to locate DNA markers linked to quantitative trait loci (QTL) involved in the inheritance of important agronomic traits. These putative QTL usually explain a significant proportion of the phenotypic variance of a trait. Under the assumption of equal heritability for all detected QTL, their explained proportion of the genotypic variance was also assessed. Based on this proportion and on the heritability of the trait, the efficiency of marker assisted selection (MAS) compared with classical phenotypic selection (CPS) was determined. Whereas MAS was successfully applied in some breeding programs (Fridman et al. 2000; Yousef and Juvik 2001), it failed in other programs (Openshaw and Frascarolli 1997; Bouchez et al. 2002), mainly because of an overestimation of the genotypic variance explained (Utz and Melchinger 1994; Beavis 1998). This overestimation is partly due to a restricted population size, a limited genome coverage, and a non congruency of the QTL over generations and populations.

In faba bean breeding, genetic linkage maps were recently developed to identify QTL for seed quality and resistance to biotic stress (Román et al. 2002, 2003), but none for tolerance to abiotic stress.

The objective of this study was (1) to develop a genetic linkage map on a faba bean RIL population, (2) to identify, map, and assess the genetic effect of QTL associated with frost tolerance and related trait, (3) to reassess the proportion of the genotypic variance explained by all putative QTL via resampling, and (4) to determine the relative efficiency of MAS vs. CPS for frost tolerance.

\section{Materials and methods}

Plant material

Two frost tolerant inbred lines were used as parents: Côte d'Or 1 (inbred line derived from the winterhardy French landrace Côte d'Or; yellow (buff) seed coat), and BeanPureLine 4628 (BPL, Chinese inbred line from the ICARDA germplasm collection; green seed coat). The findings of Duc and PetitJean (1995) and the provenience of both lines from distant geographical areas was taken as promise of a large segregation for frost tolerance in the progeny of this cross. Randomly chosen F2 plants were advanced by single seed descent to produce $\mathrm{N}=101 \mathrm{~F} 6$ derived recombinant inbred lines (RIL). Frost tolerance in artificial frost tests and fatty acid composition in leaves were measured on these lines and on their parental lines with and without hardening.

During germination and emergence the temperature was kept at $8^{\circ} \mathrm{C}$ days $/ 0^{\circ} \mathrm{C}$ nights for 3 weeks to 
produce hardened seedlings, and at $18^{\circ} \mathrm{C}$ days $/ 15^{\circ} \mathrm{C}$ nights to produce unhardened seedlings. For every genotype, four seedlings were grown in a pot $(17 \times 17 \times 17 \mathrm{~cm})$ filled with $5 \mathrm{~kg}$ of soil $(1: 1$ mixture of sand and compost). The soil was kept between $70 \%$ and $80 \%$ of its water capacity.

Phenotypic data

\section{Artificial frost tests}

Unhardened and hardened frost tolerance of RIL were assessed in a frost chamber $(2 \times 2 \times 2 \mathrm{~m})$. At the two expanded leaves stage, the plants were tested for their frost tolerance in both treatments (cf. Arbaoui and Link 2007). The "Area Under Symptom Progress Curve" was calculated and considered as the trait expression of frost tolerance.

\section{Fatty acid analyses}

First leaves of hardened and unhardened seedlings were analyzed for fatty acid composition of their total lipid content. The experimental protocol used to extract and analyze fatty acids was according to Arbaoui et al. (2008).

\section{Marker data}

Leaf tissue from the 101 F6 RIL and the two parental lines was collected and freeze dried. Genomic DNA was extracted as described by the Nucleon and PhytoPure extraction kit (Amersham Biosciences Corp., 2003). To construct the genetic linkage map, RAPD primers were used. The RAPD analyses were performed following the experimental protocol of Williams et al. (1990), with slight modifications (Torres et al. 1993). The two parental lines were screened for polymorphism with a total of 144 RAPD primers. Forty-four primers revealing intense and clearly scorable polymorphic bands were selected to further analyse the present F6 population.

Additionally to the molecular markers, the monogenic trait yellow seed coat $(Y g)$ was used as morphological marker.
Statistics

\section{Phenotypic data}

For artificial frost tests, the 101 F6 RIL and the two parental lines were analyzed in three experiments in both treatments (hardened and unhardened). Two experiments were laid out as lattice with three replicates and one with two; one replicate corresponding to one load of the plant growth chamber. In both treatments, the lattice adjusted AUSPC mean across all experiments of each inbred line was considered as the phenotypic expression of frost tolerance.

For fatty acid analyses, in both treatments the 101 F6 RIL and the two parental lines were randomized in three experiments. Each experiment was laid out as randomized complete blocks with two replicates; one replicate of a genotype comprising a mixture of first leaves from two plants. In both treatments, the mean across the replicates and the experiments was calculated for each identified fatty acid. From these means and in each fatty acid the difference between hardened and unhardened content was also calculated and considered as the hardening response.

In order to determine significant sources of variation and to assess heritability $\left(\mathrm{h}^{2}=\frac{\sigma_{G}^{2}}{\sigma_{P}^{2}}\right)$, an analysis of variance was performed using Plabstat (Utz 1991). For fatty acids, to test the hardening response for significance and to quantify its heritability, the genotype $\times$ treatment interactions was taken as source of variation.

In order to test for a useful relationship between (1) content and changes in fatty acid composition and (2) frost tolerance, correlation analyses were performed between these traits.

\section{Linkage analysis}

For each segregating marker, a $\chi^{2}$ analysis was used to test for deviations from the expected 1:1 segregation ratio in the RIL population. The markers not showing normal diploid segregation $(P>0.01)$ were excluded from further analysis. The linkage map was constructed by MAPMAKER V 2.0 (Lander et al. 1987) using the LOD value of 3 and recombination fraction of $\mathrm{r}<0.30$ as thresholds. Recombination 
fractions were converted to centiMorgans (cM) using the mapping function of Haldane (1919).

\section{QTL analyses}

The QTL mapping and estimation of their effects were performed using PLABQTL (Utz and Melchinger 1996). Analyses were performed with means of the 101 F6 RIL for all measured traits. The method of composite interval mapping (CIM) with cofactors (Jansen and Stam 1994) was used for detecting, mapping, and characterising QTL. To declare a putative QTL, the minimum LOD score was fixed according to the Bonferroni correction. Thus, in this study, with 111 marker intervals tested and two degrees of freedom, the LOD threshold was fixed to 3.34 to ensure the experiment-wise significance level of $95 \%$. Two putative QTL if inherited from the same parent and if mapped within a distance of $20 \mathrm{cM}$ were declared congruent (Melchinger et al. 1998).

The proportion of the phenotypic variance explained by a putative QTL was determined by its partial coefficient of determination $\mathrm{R}^{2}$. The phenotypic proportion explained by all detected QTL was taken as the adjusted coefficient of determination $\left(\mathrm{R}_{\mathrm{adj}}^{2}\right.$; Hospital et al. 1997) of the full model in the final simultaneous fit as described by Utz et al. (2000). Assuming that the heritability of the studied trait was the same for all detected QTL, the corresponding genotypic proportion explained from the whole data set $\left(\mathrm{p}_{\mathrm{DS}}\right.$; Schön et al. 2004) was determined from the ratio:

$p_{D S}=\frac{R_{a d j}^{2}}{h^{2}}$.

In order to avoid an overestimation of $\mathrm{p}_{\mathrm{DS}}$ due to the restricted population size $(\mathrm{N}=101)$ used in this study, a re-sampling method, the fivefold crossvalidation (CV; Utz et al. 2000), was performed as implemented in PLABQTL. A total of 1,000 replicated CV runs with 200 randomizations for assigning genotypes to the respective sub-samples was performed to obtain asymptotically unbiased estimates of the phenotypic $\left(\mathrm{R}_{\mathrm{adj}-\mathrm{CV}}^{2}\right)$ and genotypic variance $\left(\mathrm{p}_{\mathrm{TS}}\right)$ explained by all detected QTL (Utz et al. 2000; Schön et al. 2004).

These estimates were used to assess the prospects of pure MAS (based on marker data) and of combined
MAS (cMAS; based on phenotypic and marker data) for frost tolerance as relative efficiency (RE) of these two approaches compared to classicial phentopyic selection. Two pertinent formulae of Lande and Thompson (1990) were applied for this purpose:

Pure MAS,

$\mathrm{RE}=\sqrt{\frac{\mathrm{p}_{\mathrm{i}}}{\mathrm{h}_{\mathrm{i}}^{2}}}$

Combined MAS,

$R E=\sqrt{\frac{p_{i}}{h_{i}^{2}}+\frac{\left(1-p_{i}\right)^{2}}{\left(1-h_{i}^{2} \cdot p_{i}\right)}}$

\section{Results}

Phenotypic data

\section{Artificial frost tests}

Exposure to hardening had a significant effect on frost tolerance across lines and replicates. Although the two parental lines had similar AUSPC in both treatments (details not shown), the significant differences among the 101 F6 RIL proved that Côte d'Or 1 and BPL 4628 were genetically different for frost tolerance (Table 1). Moreover, the identification of 27 RIL (including F6-33, F6-95, and F6-69) significantly better performing than both parental lines corroborated the complementarities of Côte d'Or/1 and BPL 4628 for alleles coding for frost tolerance. The heritability of genotypes for mean frost tolerance was high $\left(\mathrm{h}^{2}=0.778\right)$, and intermediate for hardened $\left(\mathrm{h}^{2}=0.656\right)$ and unhardened $\left(\mathrm{h}^{2}=0.669\right.$; details not shown) frost tolerance. The significant genotype $\times$ treatment interactions showed that genotypes were different for their hardening response (Fig. 1).

\section{Fatty acid analyses}

Among the 10 fatty acids identified, six were further analyzed because they represented more than $95 \%$ of the total composition: palmitic acid (16:0), stearic acid (18:0), oleic acid (18:1), linoleic acid (18:2), linolenic acid (18:3), and stearidonic acid (18:4). The main fatty acid in leaves was 18:3 (Table 2). 
Table 1 Analysis of variance of frost tolerance of 101 F6 recombinant inbred lines from the cross Côte d'Or $1 \times$ BPL 4628 (AUSPC, area under symptom progress curve)

\begin{tabular}{llrc}
\hline Sources of variation & DF & MS $\left(\times 10^{4}\right)$ & \multicolumn{1}{l}{$\mathrm{F}$} \\
\hline Treatments & 1 & 17970.18 & $162.28^{* *}$ \\
Experiments/T & 4 & 110.74 & $139.73^{* *}$ \\
Genotypes & 100 & 3.57 & $4.50^{* *}$ \\
Genotype $\times$ treatment & 100 & 1.09 & $1.37^{*}$ \\
G $\times$ E/T & 331 & 0.79 & $1.59^{* *}$ \\
Error & 553 & 0.50 & \\
Heritability of G & 0.778 & & \\
Heritability of G $\times \mathrm{T}$ & 0.280 & & \\
\hline
\end{tabular}

*, **, Significant at the 0.05 and 0.01 level of probability, respectively

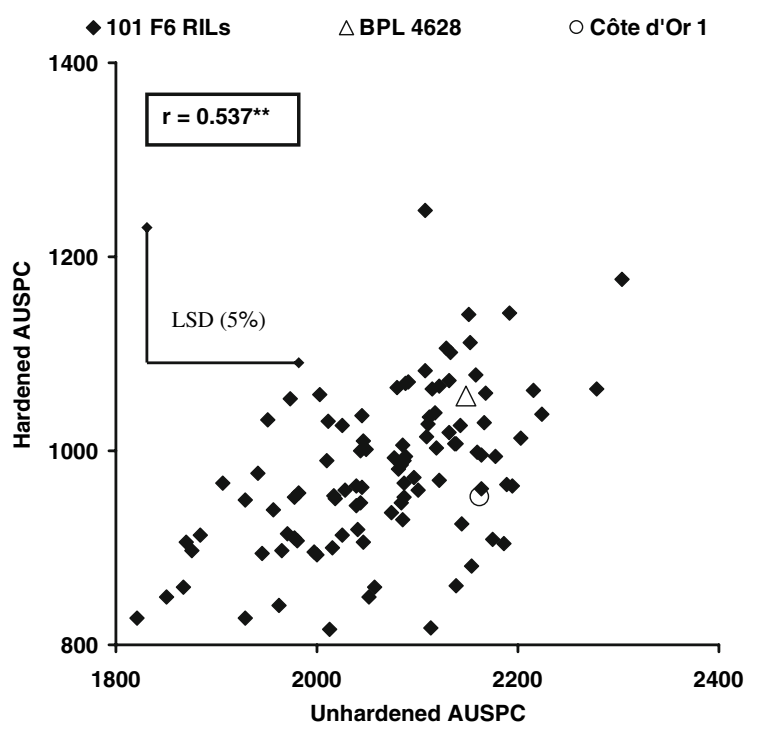

Fig. 1 Correlation between hardened AUSPC and unhardened AUSPC (units ${ }^{\circ} \mathrm{C} \mathrm{h}$ ) based on $101 \mathrm{~F} 6$ recombinant inbred lines derived from the cross between Côte d'Or $1 \times$ BPL 4628

Table 2 Mean fatty acid composition (\%) of hardened and unhardened first leaf across genotypes and repetitions of 101 F6 recombinant inbred lines from the cross Côte d' Or $1 \times$ BPL 4628

\begin{tabular}{lcccccc}
\hline Treatment & $16: 0$ & $18: 0$ & $18: 1$ & $18: 2$ & $18: 3$ & $18: 4$ \\
\hline Hardened & 10.02 & 1.41 & 4.61 & 20.58 & 55.26 & 5.07 \\
Unhardened & 10.58 & 1.29 & 8.22 & 17.44 & 52.30 & 7.09 \\
Average & 10.30 & 1.35 & 6.41 & 19.01 & 53.78 & 6.08 \\
\hline
\end{tabular}

Hardening had a significant effect on 18:1 and 18:2 content. Although a marked increase was observed for 18:3 content due to hardening, it was not significant. Across treatments and replicates, the lines were significantly different for their fatty acid composition. The heritability of the genotypes and their hardening response were very different among the fatty acids (Table 3 ). The ANOVA for fatty acid composition in each treatment revealed significant differences among the RIL. The heritability estimates were $0.297<\mathrm{h}^{2}<0.884$; the highest being observed in unhardened 18:1 content.

Oleic acid content in unhardened leaves was significantly correlated with polyunsaturated fatty acid content in unhardened leaves $\left(\mathrm{r}=-0.841^{* *}\right)$ and to the increase of polyunsaturated fatty acid content due to hardening $\left(\mathrm{r}=0.545^{* *}\right)$, corroborating findings of Arbaoui and Link (2007). Thus, high initial amount of 18:1 led to higher increase of 18:2 + 18:3, likely from its de-saturation due to hardening.

\section{Correlation analyses}

Significant correlations were found between 18:1 $\left(\mathrm{r}=0.318^{* *}\right.$; Fig. 2$)$ and 18:2 $+18: 3\left(\mathrm{r}=-0.231^{*}\right)$ content in unhardened leaves with unhardened AUSPC. Significant correlations were also found between unhardened 18:0 content and hardened AUSPC $\left(\mathrm{r}=0.299^{* *}\right)$. Although significant, the low correlation values prevented the use of fatty acid composition as a tool to directly select for frost tolerance.

\section{Linkage map}

The 44 RAPD primers used in the analysis resolved 216 scorable polymorphic markers. Out of 195 RAPD markers showing normal diploid segregation $(P>0.01)$ in the RIL population, 131 could be mapped into 21 linkage groups. One additional morphological marker (Seed Coat Colour) has also been mapped. Linkage groups consisted of 2-18 marker loci covering $1635.39 \mathrm{cM}$ of the faba bean genome with the mean inter-marker distance of $14.73 \mathrm{cM}$ (Fig. 3).

QTL analyses

\section{Frost tolerance}

Frost tolerance of a plant was considered as the combination of its unhardened and hardened frost 
Table 3 Analysis of variance for main fatty acid composition (\%) of 101 F6 recombinant inbred lines from the cross Côte d'Or $1 \times$ BPL 4628. F-values and heritability

\begin{tabular}{|c|c|c|c|c|c|c|c|}
\hline Sources of variation & DF & $16: 0$ & 18:0 & $18: 1$ & $18: 2$ & $18: 3$ & $18: 4$ \\
\hline Treatments & 1 & 0.9 & 0.7 & $62.3 * *$ & $12.4^{*}$ & 2.6 & $161.3 * *$ \\
\hline Experiments/T & 4 & $58.0 * *$ & $155.4 * *$ & $127.4 * *$ & $108.5^{* *}$ & $140.9 * *$ & 1.3 \\
\hline Replicates $/ \mathrm{E} \times \mathrm{T}$ & 6 & $8.3 * *$ & $3.4 * *$ & $2.3^{*}$ & $3.0 * *$ & $8.4 * *$ & $19.0 * *$ \\
\hline Genotypes & 100 & $5.6 * *$ & $4.7 * *$ & $10.8 * *$ & $5.2 * *$ & $5.7 * *$ & $2.2 * *$ \\
\hline $\mathrm{G} \times \mathrm{T}$ & 100 & $1.5 * *$ & $2.8 * *$ & $4.1 * *$ & $2.8 * *$ & $2.5 * *$ & 1.1 \\
\hline $\mathrm{G} \times \mathrm{E} / \mathrm{T}$ & 400 & $2.3 * *$ & $2.1 * *$ & $4.1 * *$ & $3.7 * *$ & $4.4 * *$ & $2.6 * *$ \\
\hline Error & 600 & & & & & & \\
\hline Heritability of $\mathrm{G}$ & 0.82 & 0.79 & 0.91 & 0.81 & 0.81 & 0.53 & \\
\hline Heritability of $\mathrm{G} \times \mathrm{T}$ & 0.32 & 0.64 & 0.75 & 0.64 & 0.61 & 0.07 & \\
\hline
\end{tabular}

*,**, Significant at the 0.05 and 0.01 level of probability, respectively

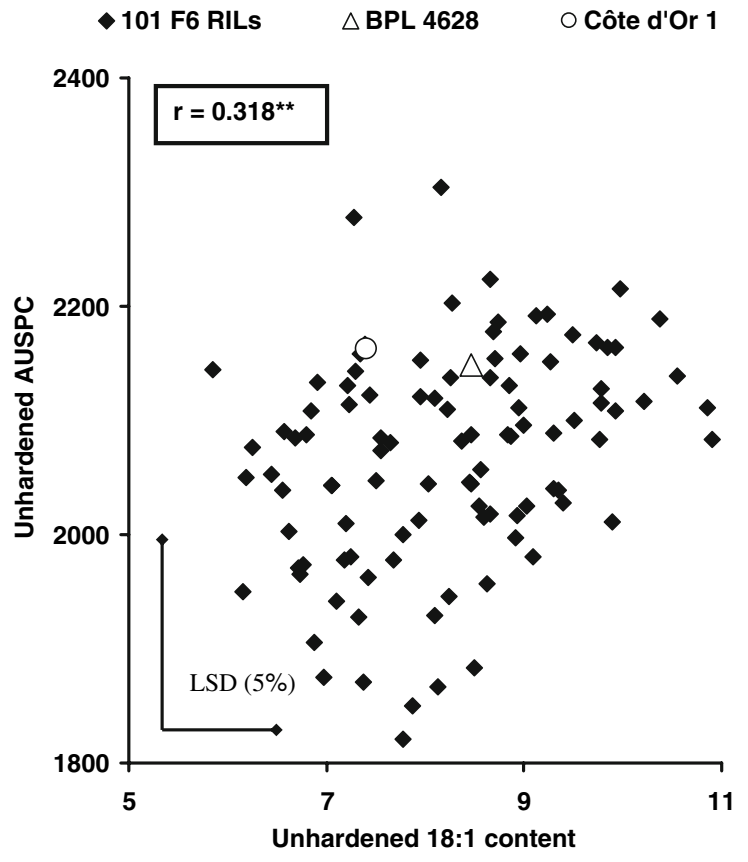

Fig. 2 Correlation between 18:1 content in unhardened leaves (\% of total fatty acid content) and unhardened AUSPC (units ${ }^{\circ} \mathrm{C}$ h) based on $101 \mathrm{~F} 6$ recombinant inbred lines derived from the cross between Côte d'Or $1 \times$ BPL 4628

tolerance. Three putative QTL were detected for the unhardened AUSPC. One favourable allele was inherited from BPL and two from Côte d'Or 1. The phenotypic variance explained by the three QTL was $27.2 \%$, which corresponded to $40.7 \%$ of the genotypic variance. The fivefold cross-validation (CV) tests revealed that there was a strong bias included in the estimate of the explained proportion of the genotypic variance $\left(\mathrm{p}_{\mathrm{TS}}=8.6 \%\right)$. For the hardened
AUSPC, two putative QTL were detected that were inherited from the European inbred line Côte d'Or 1. These QTL explained $14.3 \%$ of the phenotypic variance, and $21.8 \%$ of the genotypic variance (Table 4). The proportion of the genotypic variance explained was dramatically reduced by $\mathrm{CV}$ to $\mathrm{p}_{\mathrm{TS}}=$ $1.0 \%$. The QTL U_AUSPC-2 associated to unhardened frost tolerance and the QTL H_AUSPC-2 associated to hardened frost tolerance were located on the same linkage group (LG10).

\section{Fatty acid composition}

In order to avoid overestimation of the genotypic variance explained, it was decided to discard the following fatty acid traits due to their low heritability $\left(\mathrm{h}^{2}<0.50\right)$ : hardened and unhardened 18:4 content, along with changes in 16:0 and in 18:4 content due to hardening.

Without hardening, a range of one to three putative QTL was detected for each fatty acid. Across fatty acids, all detected QTL explained $2.4-51.4 \%$ of the phenotypic variance and $3.7-58.2 \%$ of the genotypic variance. However, only the QTL for stearic (U_C18:0) and oleic (U_C18:1) acid content in unhardened leaves explained substantial proportion of phenotypic and genotypic variation after crossvalidation procedure. The highest $\mathrm{p}_{\mathrm{DS}}$ was observed for unhardened 18:1 content. In this case, CV showed that $40.6 \%$ could be accounted to the unbiased explained proportion of the genotypic variance.

With hardening, QTL for 16:1, 18:0, 18:1 and 18:3 have been detected but the cross-validation revealed 


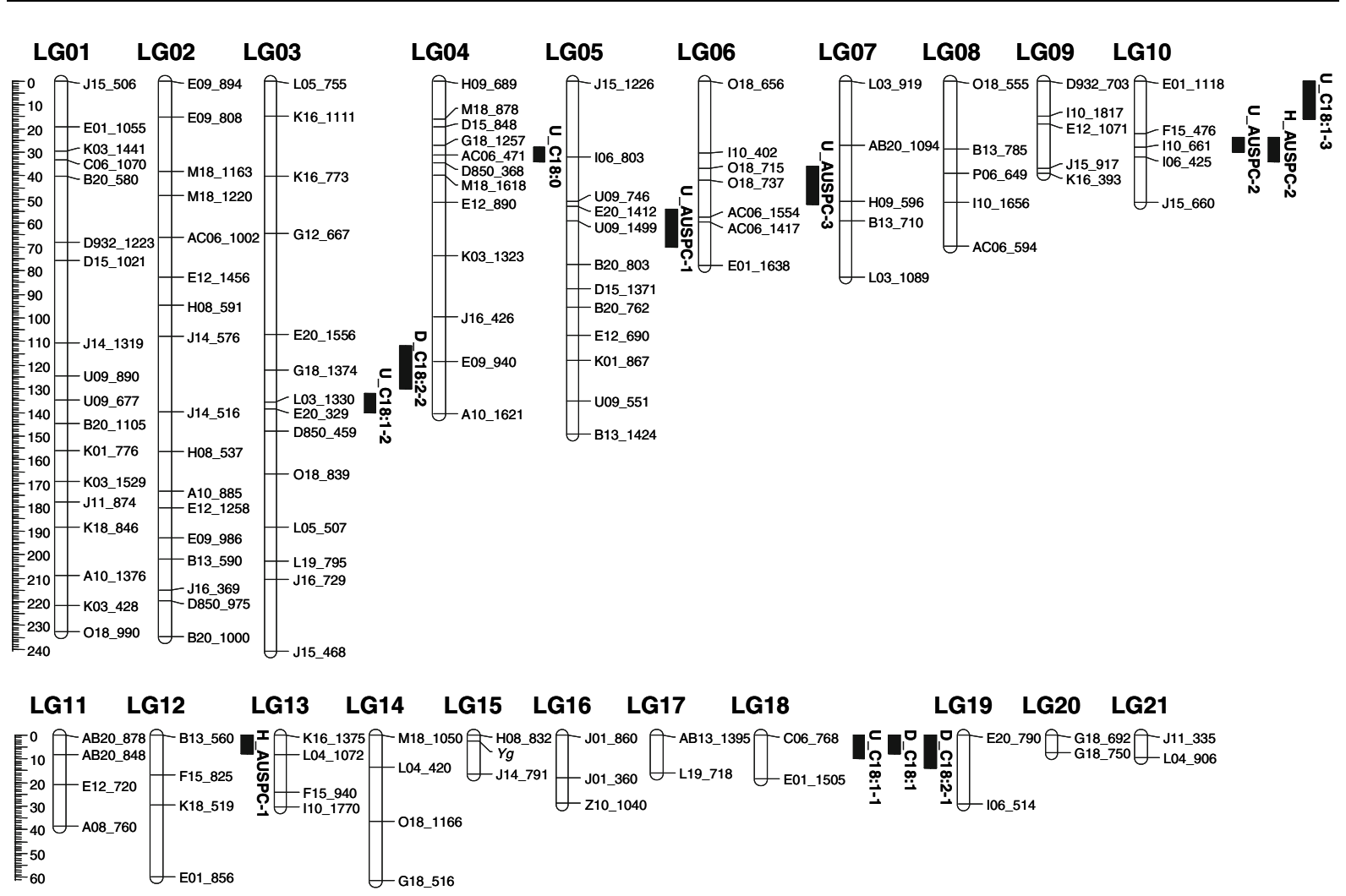

Fig. 3 Genetic linkage map of faba bean based on 101 F6 recombinant inbred lines derived from the cross between Côte d'Or 1 and BPL 4628. Map positions are given in $\mathrm{cM}$ using the

that the proportion explained by these QTL was extremely overestimated and were disregarded in the analysis.

For the hardening response, one putative QTL was associated with changes in 18:1 content that explained $42.8 \%$ (20.3\% after CV) of the genotypic variance. Two putative QTL were detected for hardening response of 18:2 content explaining $33.6 \%$ (and $7.78 \%$ after CV) of the genotypic variance. On LG18, 3 QTL associated with unhardened 18:1 content, with changes due to hardening in 18:1 and in 18:2 content were mapped within the same marker interval.

\section{Discussion}

In faba bean, frost tolerance was found to be highly heritable due to large additive effects (Duc and PetitJean 1995). In a large population of recombinant inbred lines segregating for frost tolerance, the power
Haldane mapping function. Bar positions indicate locations of quantitative trait loci with 1-LOD support interval

of detection is therefore expected to be high. In this study, based on 101 F6 RIL, a total of five putative QTL was detected for frost tolerance. For unhardened frost tolerance, favourable alleles were inherited from both parents, as expected from their similar phenotypic frost tolerance. This finding proposed complementarities of the parents for other nondetected QTL linked to frost tolerance genes.

Despite significant phenotypic differences among RIL, only a limited proportion of the frost tolerance (hardened and unhardened) was explained, presumably (1) since not all possible allele recombinations for frost tolerance were covered, likely from the small population size and (2) since with many more linkage groups than chromosomes $(21>6)$ we have to suspect gaps in the linkage map, possibly containing further relevant loci. Since the unbiased proportion of the genotypic variance explained was low, it may be proposed that the frost tolerance is a polygenic trait which might not be controlled by few major QTL. Simulations (Beavis 1998) and experimental studies 
Table 4 Parameters associated with putative quantitative trait loci (QTL) for frost tolerance and fatty acid composition in both treatments assessed from genotypic and phenotypic data of 101 F6 recombinant inbred lines from the cross Côte d'Or $1 \times$ BPL 4628

\begin{tabular}{|c|c|c|c|c|c|c|}
\hline Trait & QTL & Marker interval & Position $^{a}$ & LOD & $\left(\mathrm{R}^{2}\right)^{\mathrm{b}}$ & $\operatorname{add}^{\mathrm{c}}$ \\
\hline U_AUSPC & $\begin{array}{l}\text { U_AUSPC-1 } \\
\text { U_AUSPC-2 } \\
\text { U_AUSPC-3 }\end{array}$ & $\begin{array}{l}\text { U09_1499/B20_803 } \\
\text { F15_476/I10_661 } \\
\text { O18_715/O18_737 } \\
\text { Full model }^{\mathrm{d}} \\
\text { Cross-validation }\end{array}$ & $\begin{array}{l}\text { LG05: } 60 \\
\text { LG10: } 28 \\
\text { LG06: } 40\end{array}$ & $\begin{array}{l}4.64 \\
4.30 \\
3.61 \\
8.33\end{array}$ & $\begin{array}{l}15.1 \\
11.5 \\
11.6 \\
27.2(40.7)^{\mathrm{e}} \\
5.7(8.6)^{\mathrm{f}}\end{array}$ & $\begin{array}{r}-33.97 \\
-28.37 \\
30.31\end{array}$ \\
\hline H_AUSPC & $\begin{array}{l}\text { H_AUSPC-1 } \\
\text { H_AUSPC-2 }\end{array}$ & $\begin{array}{l}\text { B13_560 } \\
\text { I10_661/I06_425 } \\
\text { Full model } \\
\text { Cross-validation }\end{array}$ & $\begin{array}{l}\text { LG12: } 0 \\
\text { LG10: } 30\end{array}$ & $\begin{array}{l}5.99 \\
5.77 \\
4.29\end{array}$ & $\begin{array}{l}10.0 \\
9.7 \\
14.3(21.8) \\
0.7(1.0)\end{array}$ & $\begin{array}{l}-25.51 \\
-25.66\end{array}$ \\
\hline U_C18:0 & U_C18:0 & $\begin{array}{l}\text { AC06_471/D850_368 } \\
\text { Full model } \\
\text { Cross-validation }\end{array}$ & LG04: 32 & $\begin{array}{l}5.54 \\
5.38\end{array}$ & $\begin{array}{r}21.8 \\
20.2(30.4) \\
9.9(14.9)\end{array}$ & -0.05 \\
\hline U_C18:1 & $\begin{array}{l}\text { U_C18:1-1 } \\
\text { U_C18:1-2 } \\
\text { U_C18:1-3 }\end{array}$ & $\begin{array}{l}\text { C06_768/E01_1505 } \\
\text { L03_1330/E20_329 } \\
\text { E01_1118/F15_476 } \\
\text { Full model } \\
\text { Cross-validation }\end{array}$ & $\begin{array}{l}\text { LG18: } 4 \\
\text { LG03: } 136 \\
\text { LG10: } 4\end{array}$ & $\begin{array}{r}7.62 \\
6.44 \\
3.69 \\
17.03\end{array}$ & $\begin{array}{l}35.9 \\
24.2 \\
13.0 \\
51.4(58.2) \\
35.9(40.6)\end{array}$ & $\begin{array}{r}0.69 \\
-0.45 \\
0.38\end{array}$ \\
\hline D_C18:1 & D_C18:1 & $\begin{array}{l}\text { C06_768/E01_1505 } \\
\text { Full model } \\
\text { Cross-validation }\end{array}$ & LG18: 0 & $\begin{array}{l}6.27 \\
9.11\end{array}$ & $\begin{array}{l}26.4 \\
32.2(42.8) \\
15.3(20.3)\end{array}$ & -0.57 \\
\hline D_C18:2 & $\begin{array}{l}\text { D_C18:2-1 } \\
\text { D_C18:2-2 }\end{array}$ & $\begin{array}{l}\text { C06_768/E01_1505 } \\
\text { E20_1556/G18_1374 } \\
\text { Full model } \\
\text { Cross-validation }\end{array}$ & $\begin{array}{l}\text { LG18: } 6 \\
\text { LG03: } 120\end{array}$ & $\begin{array}{l}4.93 \\
4.50 \\
6.16\end{array}$ & $\begin{array}{l}23.7 \\
18.7 \\
21.5(33.6) \\
4.99(7.78)\end{array}$ & $\begin{array}{r}0.72 \\
-0.67\end{array}$ \\
\hline
\end{tabular}

Traits: U_AUSPC_-unhardened AUSPC; H_AUSPC—-hardened AUSPC; U_C18:0—-stearic acid contend in unhardened leaves; U_C18:1—oleic acid content in unhardened leaves; D_C18:1—hardening response of oleic acid content; D_C18:2—hardening response of linoleic acid content

${ }^{a}$ Linkage group and the position in cM from the top of the linkage group

b Proportion of phenotypic variation accounted for each QTL calculated by multiple regression

c The additive effect of each QTL is calculated as (mean of the Cote d'Or genotypic class- mean of BPL genotypic class). Therefore, positive values indicate that Cote d'Or carries the allele for an increase in the trait, and negative values indicate that BPL contributes the alleles for an increase in the trait

${ }^{d}$ Results of a multiple regression analysis that includes all QTL effects

e Proportion of phenotypic $\left(\mathrm{R}_{\text {adj }}^{2}\right)$ and genotypic $\left(\mathrm{p}_{\mathrm{DS}}\right)$ variation explained by the full model

${ }^{\mathrm{f}}$ Proportion of phenotypic $\left(\mathrm{R}_{\mathrm{adj}-\mathrm{CV}}^{2}\right)$ and genotypic $\left(\mathrm{p}_{\mathrm{TS}}\right)$ variation as obtained by cross-validation

(Schön et al. 2004) showed that for polygenic traits, the proportion of the unbiased genotypic variance explained by individual detected QTL was indeed low. Thus, with a larger population and similar framework map, an increase of $\mathrm{p}_{\mathrm{TS}}$ for frost tolerance would result from the increase of the power of detection rather than from the increase of partial $\mathrm{R}^{2}$ of individual QTL. Thus, in back cross breeding programs assisted by markers, since the necessary initial population size increases according to the number of markers (QTL) implemented (Hospital and Charcosset 1997), an increased power of detection might not be very useful for practical limitations unless QTL with higher $\mathrm{R}^{2}$ are detected. In comparison to previous QTL studies based on small population for polygenic traits, the low reported proportion of the genotypic variance explained of frost tolerance was due (1) to the rather strict LOD 
threshold (3.34) to declare putative QTL as proposed by Knapp (1998), and especially due (2) to the crossvalidation (Utz et al. 2000; Melchinger et al. 2005).

Putative QTL were detected to be associated with fatty acid content in unhardened leaves and with their hardening response. On LG18, the three putative QTL mapped within the same marker interval can be considered as congruent. Thus, this single region showed to be associated with the synthesis of unhardened 18:1 content and the hardening response of 18:1 and 18:2. Taking into account the pathway of polyunsaturated fatty acid synthesis (Wei et al. 2005), it is plausible to detect a single QTL, representing a locus coding for an oleoyl desaturase enzyme with a significant simultaneous effect on 18:1 decrease and 18:2 increase due to hardening. The opposite signs of the QTL effects on both traits support this conclusion. The genotypic variance of unhardened 18:1 content was to a large extent explained by three putative QTL ( $\mathrm{p}_{\mathrm{DS}}=62.9 \%$ and $\left.\mathrm{p}_{\mathrm{TS}}=40.6 \%\right)$. In comparison to the unbiased genotypic variance of frost tolerance explained, the large $\mathrm{p}_{\mathrm{TS}}$ of 18:1 content suggested that this trait is oligogenic. From simulation studies, Beavis (1998) showed for a trait controlled by 10 QTL with additive effects of equal size and a heritability of $63 \%$, it should be possible with $100 \mathrm{~F} 2$ progenies to detect $35 \%$ of all QTL that would consequently explain $35 \%$ of the genotypic variance. In this study, at equal population sample size, higher genotypic variance explained was observed apparently because (1) there are no evidences from literature that $18: 1$ content is controlled by as many loci, (2) the heritability of the trait was higher (0.884), and (3) the population type was different (F6 RIL vs. F2 progenies). From this result, the content of the other fatty acids could be as well considered as oligogenic and high power of detection would be hence expected. However, for each further fatty acid, the power of detection and the unbiased genotypic variance explained were rather low (Table 4). One reason could be the limited genome size covered by the marker loci. Indeed, 64 polymorphic markers were not mapped into LG and not used in the QTL analyses.

In the correlation analyses among the phenotypic traits, significant correlations were found between fatty acid composition, their changes due to hardening and hardened as well as unhardened frost tolerance. Because of the significant relationships among fatty acids, in each treatment, only the highest correlation between frost tolerance and fatty acid was further analyzed to avoid redundant information. For the unhardened AUSPC, the highest correlation was observed with unhardened 18:1 content $\left(\mathrm{r}=0.318^{* *}\right)$. The coefficient of regression of unhardened AUSPC on unhardened 18:1 content was significant and $10.09 \%$ of the adjusted phenotypic variance of unhardened frost tolerance was explained by this fatty acid. Using the heritability of both traits, the genotypic variance explained by unhardened 18:1 content was assessed to $17.06 \%$. One of the putative QTL detected for these two traits was mapped on LG10 within an interval distance of $24 \mathrm{cM}$. Both QTL increased respectively unhardened 18: 1 content $(+0.4 \%)$ and unhardened frost tolerance (-28.4 scoreunit ${ }^{\circ} \mathrm{C} \mathrm{h}$ ); thus corroborating the phenotypic correlation between these two traits. Although located at more than $20 \mathrm{cM}$ from each other, it is likely that these two QTL are congruent. Thus, this "one" QTL explained 9.7\% of the adjusted phenotypic variance of unhardened frost tolerance; corresponding to $14.49 \%$ of the adjusted genotypic variance explained. The maximum of the unhardened frost tolerance genotypic variance explainable by unhardened 18:1 content being 17.06\%, this QTL seemed to explain main part of it. For hardened frost tolerance, although significant correlations were found between hardened AUSPC and unhardened 18:0 content $\left(\mathrm{r}=0.299^{* *}\right)$, hardened 18:3 content $\left(\mathrm{r}=-0.221^{*}\right)$, QTL analysis did not reveal putative fatty acid QTL involved in the inheritance of hardened frost tolerance.

Under the assumption of equal heritability of all detected QTL for one trait and equal selection intensity, the formulae of Lande and Thompson (1990) were applied to determine the relative efficiency (RE) of pure and combined MAS for unhardened and hardened frost tolerance (cMAS; Table 5). The relative efficiency of the pure MAS was lower than 1 irrespective of the proportion of the genotypic variance explained. On the other hand, the RE of the combined MAS was slightly higher than 1 .

For a higher pure MAS efficiency than classical phenotypic selection on the studied population, the power of detection should dramatically increase in order that $\mathrm{p}_{\mathrm{DS}}$ or $\mathrm{p}_{\mathrm{TS}}$ exceed the heritability. However, simulation and experimental studies showed that for polygenic trait although large population size 
Table 5 Relative efficiency (RE) of marker assisted selection (MAS) for frost tolerance based on pure MAS or combined MAS using phenotypic and marker data based on 101 F6 recombinant inbred lines derived from the cross between Côte d'Or $1 \times$ BPL 4628

\begin{tabular}{llll}
\hline Method & $\begin{array}{l}\text { Explained } \\
\text { proportion (p) }\end{array}$ & $\begin{array}{l}\text { Unhardened } \\
\text { AUSPC } \\
\text { 3 QTL }\end{array}$ & $\begin{array}{l}\text { Hardened } \\
\text { AUSPC } \\
\text { 2 QTL }\end{array}$ \\
\hline \multirow{2}{*}{ Pure MAS } & $\mathrm{p}_{\mathrm{DS}}$ & 0.78 & 0.58 \\
& $\mathrm{p}_{\mathrm{TS}}$ & 0.37 & 0.12 \\
\multirow{3}{*}{$\mathrm{cMAS}$} & $\mathrm{p}_{\mathrm{DS}}$ & 1.05 & 1.02 \\
& $\mathrm{p}_{\mathrm{TS}}$ & 1.01 & 1.00 \\
\hline
\end{tabular}

are used, the genotypic proportion explained does not exceed the heritability (Beavis 1998; Micic et al. 2004; Schön et al. 2004; Vales et al. 2005). Thus, in such case, the classical phenotypic selection could be expected to be more efficient than pure MAS. On the other hand, in case of (1) congruent QTL over generations and populations, (2) low heritability, and (3) lower costs to develop marker data than phenotypic data, the efficiency of pure MAS on other material than the studied one is expected higher than the classical phenotypic selection (CPS; Moreau et al. 1998; Lange and Whittaker 2001). Indeed, the costs due to the high number of experiments required to reach a heritability of 0.663 for frost tolerance were high. If the present marker data were available and only one experiment with three replicates was performed, pure MAS, using $\mathrm{p}_{\mathrm{DS}}$, would have been more efficient than CPS for unhardened frost tolerance $(\mathrm{RE}=1.21$; further details not shown).

Combined MAS was, based on $\mathrm{p}_{\mathrm{DS}}$ and $\mathrm{p}_{\mathrm{TS}}$, at least as efficient as CPS, even on the studied population. Similarly to pure MAS, this efficiency increased if with the same marker data, the selection was applied on data from one experiment with three replicates $\left(\mathrm{RE}=1.37\right.$ and 1.12 with $\mathrm{p}_{\mathrm{DS}}$ and 1.08 and 1.01 with $\mathrm{p}_{\mathrm{TS}}$ for unhardened and hardened frost tolerance, respectively). Several studies indeed proposed to use combined MAS in breeding programs (Romagosa et al. 1999), especially on large populations at the first generations (Hospital et al. 1997).

The putative QTL detected for fatty acids in leaves and for the potential oleoyl desaturase enzyme opened good perspectives in the understanding of physiological traits involved in the mechanisms of adaptation to hardening. The QTL analysis for frost tolerance proposed that the trait is controlled by several QTL with small effects. Based on the five putative QTL detected for unhardened and hardened frost tolerance, the RE of combined MAS suggested good prospects, and particularly for mass selection on large population sets and at early generations. However, further studies should be undertaken with larger populations to validate these five QTL, to increase the power of detection, and to consequently increase the proportion of the genotypic variance explained. In a larger scale, this QTL map mainly constructed for frost tolerance could as well be used to study faba bean drought tolerance, since these two traits share several basic physiological features.

Acknowledgements This work was supported by funds from the commission of the European Communities, specific Research Program Quality of Life and Management of Living Resources, QLK5-2001-02307 and EUFABA (QLK52002-02307). It does not necessarily reflect its views and in no way anticipates the Commissions' future policy in this area. The authors thank NPZ-Lembke Company for their financial contribution.

Open Access This article is distributed under the terms of the Creative Commons Attribution Noncommercial License which permits any noncommercial use, distribution, and reproduction in any medium, provided the original author(s) and source are credited.

\section{References}

Arbaoui M, Link W (2007) Effect of hardening on frost tolerance and fatty acid composition of leaves and stems of a set of faba bean (Vicia faba L.) genotypes. Euphytica. doi:10.1007/s10681-007-9521-4

Arbaoui M, Balko C, Link W (2008) Study of faba bean (Vicia faba L.) winter-hardiness and development of screening methods. Field Crops Res 106:60-67

Badaruddin M, Meyer DW (2001) Factors modifying frost tolerance of legume species. Crop Sci 41:1911-1916

Beavis WD (1998) QTL analyses: power, precision, and accuracy. In: Paterson AH (ed) Molecular dissection of complex traits. CRC Press, Boca Raton/New York, pp $145-162$

Bouchez A, Hospital F, Causse M, Gallais A, Charcosset A (2002) Marker-assisted introgression of favourable alleles at quantitative trait loci between maize elite lines. Genetics 162:1945-1959

Chandrasekar V, Sairam RK, Srivastava GC (2000) Physiological and biochemical responses of hexaploid and tetraploid wheat to drought stress. J Agron Crop Sci 185:219-227

Cyril J, Powell GL, Duncan RR, Baird WV (2002) Changes in membrane polar lipid fatty acids of Seashore Paspalum in 
response to low temperature exposure. Crop Sci 42:20312037

Davis DL, Gilbert WB (1970) Winter hardiness and changes in soluble protein fractions of bermudgrass. Crop Sci 10:7-9

Dörffling K, Dörffling H, Lesselich G, Luck E, Zimmermann C, Melz G, Jürgens HU (1997) Heritable improvement of frost tolerance in winter wheat by in vitro-selection of hydroxyproline-resistant proline overproducing mutants. Euphytica 93:1-10

Duc G, PetitJean F (1995) Study of inheritance of freezing tolerance in Vicia faba L. 2nd European Conference on Grain Legumes. Copenhagen, Denmark, 11-15 July 1995

Fridman E, Pleban T, Zamir D (2000) A recombination hotspot delimits a wild-species quantitative trait locus for tomato sugar content to $484 \mathrm{bp}$ within an invertase gene. Proc Natl Acad Sci USA 97:4718-4723

Haldane JBS (1919) The combination of linkage values, and the calculation of distance between the loci and the linked factor. J Genet 8:299-309

Herzog H (1987) A quantitative method to assess freezing resistance in faba beans. J Agron Crop Sci 158:195-204

Hospital F, Charcosset A (1997) Marker assisted introgression of quantitative trait loci. Genetics 147:1469-1485

Jansen RC, Stam P (1994) High resolution of quantitative traits into multiple loci via interval mapping. Genetics 136:1447-1455

Knapp S (1998) Marker assisted selection as a strategy for increasing the probability of selecting superior genotypes. Crop Sci 38:1164-1174

Lande R, Thompson R (1990) Efficiency of marker assisted selection in the improvement of quantitative traits. Genetics 124:743-756

Lander ES, Green P, Abrahamson J, Barlow A, Daly MJ, Lincoln SE, Newburg L (1987) MAPMAKER: an interaction computer program for constructing genetic linkage maps of experimental and natural populations. Genomics $1: 174-181$

Lange C, Whittaker J (2001) On prediction of genetic values in marker-assisted selection. Genetics 159:1375-1381

Levitt J (1980) Responses of plants to environmental stresses, vol 1. Academic Press, New York, pp 166-222

McKenzie JS, Paquin R, Duke SH (1988) Cold and heat tolerance. In: Hanson AA, Barnes DK, Hill RR (eds) Alfalfa and Alfalfa improvement, agronomy monograph No. 29. ASA, WI, pp 259-302

Melchinger AE, Utz HF, Schön CC (1998) Quantitative trait locus (QTL) mapping using different testers and independent population samples in maize reveals low power of QTL detection and large bias in estimates of QTL effects. Genetics 149:383-403

Melchinger AE, Utz HF, Schön CC (2005) QTL analyses of complex traits with cross validation, bootstrapping, and other biometric methods. Euphytica 137:1-11

Micic Z, Hahn V, Bauer E, Schön CC, Knapp SJ, Tang S, Melchinger AE (2004) QTL mapping of Sclerotinia midstalk-rot resistance in sunflower. TAG 109:1474-1484

Moreau L, Charcosset A, Hospital F, Gallais A (1998) Marker assisted selection efficiency in populations of finite size. Genetics 148:1353-1365

Openshaw S, Frascaroli E (1997) QTL detection and marker assisted selection for complex traits in maize. 52nd
Annual Corn and Sorghum Industry Research Conference. ASTA, Washington, DC, pp 44-53

Petcu E, Terbea M (1995) Proline content and the conductivity test as screening methods for frost tolerance of winter wheat. Bulg J Plant Physiol 21:3-11

Pollock CJ (1986) Fructans and the metabolism of sucrose in vascular plants. New Phytol 104:1-24

Rizza F, Crosatti C, Stanca AM, Cativelli L (1994) Studies for assessing the influence of hardening on cold tolerance of barley genotypes. Euphytica 75:131-138

Romá B, Torres AM, Rubiales D, Cubero JI, Satovic Z (2002) Mapping of quantitative trait loci controlling broomrape (Orobanche crenata Forsk.) resistance in faba bean (Vicia faba L.). Genome 45:1057-1063

Romagosa I, Han F, Ullrich SE, Hayes PM, Wesenberg DM (1999) Verification of yield QTL through realized molecular marker-assisted selection responses in a barley cross. Mol Breed 5:143-152

Román B, Satovic Z, Avila CM, Rubiales D, Moreno MT, Torres AM (2003) Locating genes associated with Ascochyta fabae resistance in Vicia faba. Aust J Agric Res 54:85-90

Santoiani CS, Tognetti JA, Pontis HG, Salerno GL (1993) Sucrose and fructan metabolism in wheat roots at chilling temperature. Physiol Plant 87:84-88

Schön CC, Utz HF, Groh S, Truberg B, Openshaw S, Melchinger AE (2004) Quantitative Trait Locus mapping based on resampling in a vast maize testcross experiment and its relevance to quantitative genetics for complex traits. Genetics 167:485-498

Stone JM, Palta JP, Bamberg JB, Weiss LS, Harbage JF (1993) Inheritance of freezing resistance in tuber bearing Solanum species: evidence for independent genetic control of non-acclimated freezing tolerance and cold acclimation capacity. Proc Natl Acad Sci USA 90:7869-7873

Thomashow MF (1999) Plant cold acclimation: freezing tolerance genes and regulatory mechanisms. Annu Rev Plant Physiol Plant Mol Biol 50:571-599

Torres AM, Weeden NF, Martin A (1993) Linkage among isozyme, RFLP and RAPD markers in Vicia faba. TAG 85:937-945

Utz HF (1991) A computer program for statistical analysis of plant breeding experiments. Institute of Plant Breeding, Seed Science and Population Genetics. University of Hohenheim

Utz HF, Melchinger AE (1994) Comparison of different approaches to interval mapping of quantitative trait loci. In: Van Ooijen JW, Jansen J (eds) Biometrics in plant breeding: applications of molecular markers. Proceedings of the ninth meeting of the EUCARPIA section biometrics in plant breeding. CPRO-DLO, Wageningen, The Netherlands, July 6-8, 1994, pp 195-204

Utz HF, Melchinger AE (1996) PLABQTL: a program for composite interval mapping of QTL. J Quant Trait Loci 2(1): $1-5$

Utz HF, Melchinger AE, Schön CC (2000) Bias and sampling error of the estimated proportion of genotypic variance explained by quantitative trait loci determined from experimental data in maize using cross validation and validation with independent samples. Genetics 154: 1839-1849 
Vales MI, Schön CC, Capettini F, Chen XM, Corey AE, Mather DE, Mundt CC, Richardson KL, Sandoval-Islas JS, Utz HF, Hayes PM (2005) Effect of population size on the estimation of QTL: a test using resistance to barley strip rust. TAG Original Paper

Wei H, Dhanaraj AL, Arora R, Rowland LJ, Fu Y, Sun L (2005) Identification of cold acclimation-responsive Rhododendron genes for lipid metabolism, membrane transport and lignin biosynthesis: importance of moderately abundant ESTs in genomic studies. Plant Cell Environ 29:558-570

Williams JGK, Kubelik AR, Livak KJ, Rafalski JA, Tingey SV (1990) DNA polymorphisms amplified by arbitrary primers are useful as genetic markers. Nucleic Acids Res 18:6531-6535

Yousef GG, Juvik JA (2001) Comparison of phenotypic and marker-assisted selection for quantitative traits in sweet corn. Crop Sci 136:1457-1468 